\title{
Repeat Activity Until Rule
}

National Cancer Institute

\section{Source}

National Cancer Institute. Repeat Activity Until Rule. NCI Thesaurus. Code C142667.

A rule that sets the conditions under which a repeating activity will stop. 